\title{
Prevention of the Adverse Effects of Aprotinin in Autologous Fibrin Glue
}

\author{
Hisahiro Yoshida and Akira KamiY** \\ Department of Pharmacy, Yamaguchi University Hospital, 1-1-1 Minami-Kogushi, Ube, Yamaguchi 755-8505, Japan. \\ Received August 7, 2000; accepted September 18, 2000
}

\begin{abstract}
To avoid the adverse effects of aprotinin (Apr) in autologous fibrin glue, we compared the inhibitory properties of four commercial anti-fibrinolytic agents (tranexamic acid (Tra), $\varepsilon$-aminocaproic acid (Ips), gabexate mesilate (Gab) and nafamostat mesilate (Naf)). The optimum conditions for the lysing of fibrin glue were an incubation temperature of $37^{\circ} \mathrm{C}$, and incubation medium containing urokinase at $100 \mathrm{U} / \mathrm{ml}$ and plasminogen at $100 \mathrm{mU} / \mathrm{ml}$ (for the washed glue), or neither (for unwashed glue). Fibrin glues without an anti-fibrinolytic agent were quickly lysed in the incubation medium, while those with an anti-fibrinolytic agent were slowly lysed dosedependently. Naf was the most potent inhibitor and had high affinity for the glue, but the other agents were poor inhibitors and had low affinity. The inhibition potency (IP) of each agent did not correlate with hydrophobicity, but a good correlation was obtained between the remaining coefficient (RC) and hydrophobicity. Naf did not affect the adhesive strength of the glue. These results indicate that Naf is the most suitable anti-fibrinolytic agent to replace Apr.
\end{abstract}

Key words fibrin glue; aprotinin; adverse effect; fibrinolysis; nafamostat mesilate

Fibrin glue generally consists of fibrinogen, fibronectin, coagulation factor XIII (F-XIII), thrombin, $\mathrm{CaCl}_{2}$, and aprotinin (Apr) as an inhibitor of the fibrinolytic system. ${ }^{1)}$ These components, except $\mathrm{CaCl}_{2}$ and Apr, are produced from human plasma collected from healthy volunteers. Fibrin glue coagulates through a physiological hemostatic mechanism and adheres to bleeding tissue. ${ }^{2)}$ Several types of fibrin glue products are commercially available, ${ }^{3)}$ but all have some risk for infection by thermostable pathogenicities, ${ }^{4,5}$ and for allergic reaction to subtype components of the glue. ${ }^{6-9)}$ To prevent these adverse effects, cryoprecipitate (Cryo) produced from a patient's own autologous plasma is recommended for use as fibrin glue. ${ }^{10,11)}$

As fibrin glue without an anti-fibrinolytic polypeptide is gradually lysed to fragments by plasmin, Apr is added to prevent the fibrinolysis and to prolong the localization of the glue in many cases. However, Apr is a heterologous polypeptide extracted from bovine tissues, and can occasionally cause a serious allergic reaction such as anaphylaxis. ${ }^{12,13)}$ To prevent this, another low molecular but less antigenic compound is needed. The purpose of this study was to identify the inhibitory properties of several commercial anti-fibrinolytic agents for the lysing of fibrin glue produced from human plasma as compared with those of Apr and to improve the safety of the product.

\section{MATERIALS AND METHODS}

Materials The thrombin, Apr, tranexamic acid (Tra), $\varepsilon$ aminocaproic acid (Ips), gabexate mesilate (Gab), nafamostat mesilate (Naf), urokinase, plasminogen $(\mathrm{Plg})$, and $\mathrm{CaCl}_{2}$ solutions used were Thrombin-Yoshitomi (10000 U/vial) (Yoshitomi Pharm. Co., Osaka, Japan), Trasyrol (Bayer Yakuhin Ltd., Osaka), Transamin S (Daiichi Pharm. Co., Ltd., Tokyo), Ipsilon S (Daiichi Pharm. Co., Ltd.), FOY (Ono Pharm. Co., Osaka), Futhan (Torii Pharm. Co., Ltd., Tokyo), Urokinase-Yoshitomi (Yoshitomi Pharm. Co.), and 2\% $\mathrm{CaCl}_{2}$-Otsuka (Otsuka Pharm. Co., Ltd., Tokyo), respectively. Human plasma of healthy volunteers, excluded by alanine aminotransferase (ALT) test, was obtained from the
Yamaguchi Red Cross Blood Center (Yamaguchi, Japan). All chemicals used were obtained from commercial sources and were of analytical reagent grade.

Preparation of Cryo Procedures were described in our previous paper. ${ }^{14)}$ Briefly, the human plasma was frozen at $-20^{\circ} \mathrm{C}$ in a freezer (MDF-U536, Sanyo Medica Systems Co., Osaka). It was shaken during this period by a horizontal shaker (NR-3, Taitec Co., Saitama, Japan), at a speed of 70 cycles/min. The plasma was then defrosted in a cold water bath $\left(4^{\circ} \mathrm{C}\right)$, and centrifuged at $3000 \mathrm{rpm}$ for $15 \mathrm{~min}$ at 0 $4{ }^{\circ} \mathrm{C}$. The supernatant was removed, and the precipitate was collected as Cryo. Cryo is a viscous liquid and contains $43 \pm 7 \mathrm{mg} / \mathrm{ml}$ of fibrinogen, $6.1 \pm 1.9 \mathrm{mg} / \mathrm{ml}$ of fibronectin, $15.9 \pm 4.8 \mathrm{U} / \mathrm{ml}$ of F-XIII, $2.2 \pm 0.2 \mathrm{U} / \mathrm{ml}$ of Plg, and a small amount of other plasma components. ${ }^{15)}$

Conditioning for Lysing of Fibrin Glue Preliminary experiments were done to establish optimal conditions for the lysing of fibrin glue. Briefly, a mixture $(30 \mu \mathrm{l})$ of thrombin $(100 \mathrm{U} / \mathrm{ml})$ and $\mathrm{CaCl}_{2}(0.4 \%)$ was added with the Cryo $(30 \mu 1)$ in sterilized microcentrifuge tubes (Robins Scientific, California) while agitating. ${ }^{16)}$ This mixture was incubated for $10 \mathrm{~min}$ at $37^{\circ} \mathrm{C}$, and then centrifuged at $12000 \mathrm{rpm}$ for $5 \mathrm{~min}$. Thus generated, the fibrin glue was washed with $800 \mu \mathrm{l}$ of phosphate buffered saline (PBS), and incubated in $600 \mu 1$ of PBS containing plasminogen $(5,25,100$, or $500 \mathrm{mU} / \mathrm{ml})$ and urokinase $(5,25,100$, or $500 \mathrm{U} / \mathrm{ml})$ at 4,25 , or $37^{\circ} \mathrm{C}$ for $1-$ $24 \mathrm{~h}$. The sample was then centrifuged at $12000 \mathrm{rpm}$ for $5 \mathrm{~min}$ and the supernatant removed. The precipitate was washed with $1000 \mu 1$ of cold PBS 4 times.

Lysing of Glue Containing Anti-fibrinolytic Agent The Cryo $(30 \mu \mathrm{l})$ was mixed with the anti-fibrinolytic agent $(10 \mu \mathrm{l})$ in sterilized microcentrifuge tubes (Robins Scientific), then a mixture $(20 \mu \mathrm{l})$ of thrombin $(100 \mathrm{U} / \mathrm{ml})$ and $\mathrm{CaCl}_{2}(0.5 \%)$ was added while agitating the solution. This mixture was incubated for $10 \mathrm{~min}$ at $37^{\circ} \mathrm{C}$, and then centrifuged at $12000 \mathrm{rpm}$ for $5 \mathrm{~min}$. Thus generated, the fibrin glue was washed with $800 \mu 1$ of PBS, and incubated in $1000 \mu \mathrm{l}$ of PBS containing plasminogen $(100 \mathrm{mU} / \mathrm{ml})$ and urokinase $(100 \mathrm{U} / \mathrm{ml})$ at $37^{\circ} \mathrm{C}$ for $1-24 \mathrm{~h}$. The sample was then centrifuged at $12000 \mathrm{rpm}$ for $5 \mathrm{~min}$ and the supernatant 

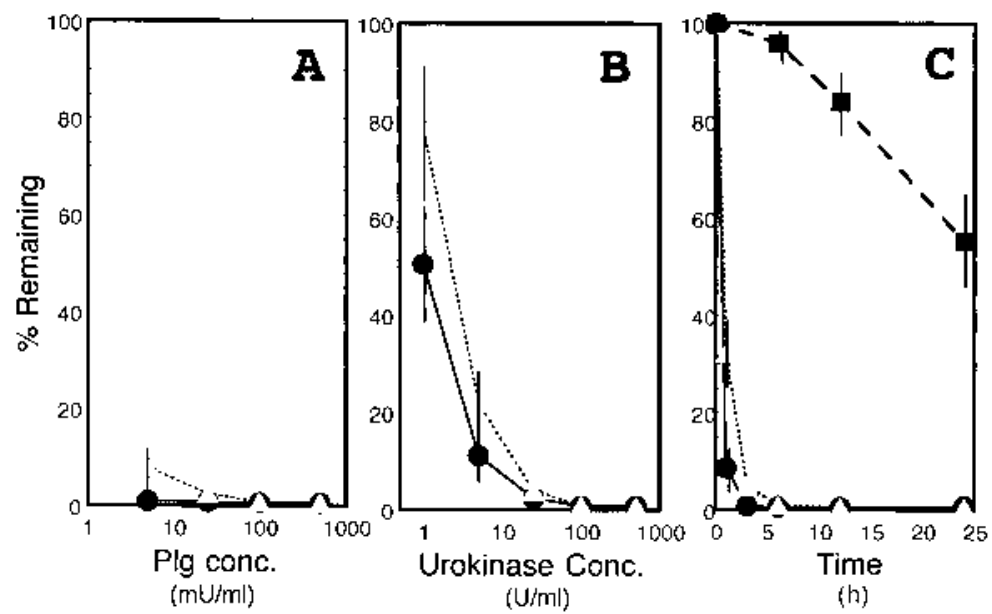

Fig. 1. Effects of Plg (A), Urokinase (B), and Temperature (C) on Lysing Properties of the Fibrin Glue

A: Fibrin glue (- unwashed, $\triangle$ : washed) was incubated in various concentrations of Plg and $100 \mathrm{U} / \mathrm{ml}$ of urokinase at $37^{\circ} \mathrm{C}$. B: Fibrin glue ( cubated in various concentrations of urokinase at $37^{\circ} \mathrm{C}$. C: Unwashed fibrin glue was incubated in $100 \mathrm{U} / \mathrm{ml}$ of urokinase at $4(\boldsymbol{\square}), 25(\triangle)$, or $37^{\circ} \mathrm{C}(\bullet)$. Values represent the mean \pm S.D. of four experiments

removed. The precipitate was washed with $1000 \mu$ of cold PBS 4 times.

Measurement of Adhesive Strength The adhesive strength of the Cryo with or without inhibitor was measured as follows: Two ground glasses of $4 \mathrm{~cm}^{2}$, bound on cubic wood with chemical adhesive, were prepared. Ten microliters of Cryo with or without anti-fibrinolytic agent was applied to one glass and $10 \mu \mathrm{l}$ of a mixture of thrombin $(50 \mathrm{U} / \mathrm{ml})$ and $\mathrm{CaCl}_{2}(0.3 \%)$ was applied to the other. The two surfaces were adhered together and pressed at $50 \mathrm{~g} / \mathrm{cm}^{2}$ for $30 \mathrm{~s}$. After $10 \mathrm{~min}$, the glasses adhered using the Cryo were fixed in a tension measuring device (SV-55, Imada Manufact. Co., Ltd., Toyohashi) and maximum tensile adhesive strength was measured. ${ }^{17)}$

Drug Hydrophobicity The hydrophobicity of each drug was represented by its retention time on the hydrophobic HPLC column (STR ODS-II $15 \mathrm{~cm} \times 4.6 \mathrm{~mm}){ }^{18)}$ The conditions used were as follows: mobile phase: $\mathrm{H}_{2} \mathrm{O} / \mathrm{CH}_{3} \mathrm{OH}=$ $65 / 35$, flow rate: $1 \mathrm{ml} / \mathrm{min}$, wavelength: $240 \mathrm{~nm}$, injection volume: $10 \mu \mathrm{l}$, temperature: $37^{\circ} \mathrm{C}$.

Analytical Methods The concentration of protein in each sample was measured using the Lowry method ${ }^{19)}$ after well washed precipitate was lysed with $1000 \mu \mathrm{l}$ of the mixture of urea $(40 \%)$ and $\mathrm{NaOH}(0.2 \mathrm{~N})$.

Calculation of Inhibitors' Parameters The concentration causing $50 \%$ inhibition of fibrinolysis $\left(\mathrm{IC}_{50}\right)$ of each anti-fibrinolytic agent was obtained from Figs. 2 and 3. Namely, a $50 \%$ inhibition line and a \% inhibition curve after $24 \mathrm{~h}$ incubation were drawn on each graph, and the concentration at the crossing point was determined as the $\mathrm{IC}_{50}$. Inhibition potency (IP) indicated the relative activity of each anti-fibrinolytic agent $v s$. that of Apr, and was calculated by dividing the $\mathrm{IC}_{50}$ of Apr with that of each inhibitor. The remaining coefficient (RC) of each anti-fibrinolytic agent indicated the relative affinity to fibrin glue, and was shown as the ratio of the $\mathrm{IC}_{50}$ of washed glue $v s$. unwashed glue for each inhibitor.

\section{RESULTS AND DISCUSSION}

Conditioning for Lysing First, basic examinations were carried out in order to establish the optimal experimental conditions for fibrinolysis. Figure 1A shows the effect of exogenous Plg on the lysis of fibrin glue. At a concentration of Plg from 5 to $500 \mathrm{mU} / \mathrm{ml}$, fibrin glue was completely degraded with $200 \mathrm{U} / \mathrm{ml}$ of urokinase after $3 \mathrm{~h}$. As a large quantity of Plg is contained in Cryo, the extent of fibrinolysis might not change with the exogenous Plg concentration. When more than $100 \mathrm{mU} / \mathrm{ml}$ of Plg was added to the incubation medium, washed glue was completely degraded after $3 \mathrm{~h}$ as true of unwashed glue, while the degradation of washed glue was slightly delayed compared with unwashed glue at a low concentration of Plg. So, unwashed glue was incubated in the medium without Plg, and washed glue was incubated in the medium with $100 \mathrm{mU} / \mathrm{ml}$ of Plg.

Figure 1B shows the effect of urokinase concentration on the fibrinolysis. The fibrinolysis was accelerated by increasing the urokinase concentration. In the presence of urokinase at more than $100 \mathrm{U} / \mathrm{ml}$, unwashed fibrin glue was completely degraded after $3 \mathrm{~h}$. Washed glue was completely degraded in $500 \mathrm{U} / \mathrm{ml}$ but not $25 \mathrm{U} / \mathrm{ml}$ of urokinase. It is therefore necessary to use more than $100 \mathrm{U} / \mathrm{ml}$ of urokinase to obtain a comfortable rate of lysis.

Figure 1C shows the effect of temperature on fibrinolysis of unwashed glue. The fibrin glue was lysed quickly and disappeared after $3 \mathrm{~h}$ at $37^{\circ} \mathrm{C}$, but the glue was lysed slowly at $25^{\circ} \mathrm{C}$ and only slightly at $4{ }^{\circ} \mathrm{C}$. On the basis of these results, the incubation temperature was set at $37^{\circ} \mathrm{C}$, and the concentration of urokinase at $100 \mathrm{U} / \mathrm{ml}$ and $\mathrm{Plg}$ at $100 \mathrm{mU} / \mathrm{ml}$ (washed glue) or neither (unwashed glue).

Lysing Properties of Fibrin Glue Containing Anti-fibrinolytic Agent To determine the effect of using anti-fibrinolytic agents to replace Apr, the lysing properties of the glue containing Apr were examined. As shown in Fig. 2, at more than 0.05 and $0.2 \mathrm{~mm}$, Apr completely inhibited the fibrinolysis of unwashed glue for 3 and $24 \mathrm{~h}$ incubation, respectively, and the inhibitory activity gradually decreased with the Apr concentration. Moreover, washed glue had a similar profile between \% inhibition and Apr concentration, but the sigmoid curves were moved to the high concentration side. The washed glue required about 3 times the Apr concentra- 


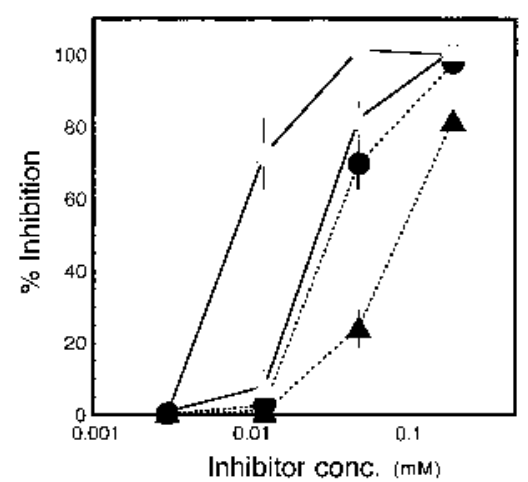

Fig. 2. Effects of Apr on Lysing Properties of the Fibrin Glues

Unwashed fibrin glue was incubated in $100 \mathrm{U} / \mathrm{ml}$ of urokinase at $37^{\circ} \mathrm{C}$ for $3(\mathrm{O})$ or $24 \mathrm{~h}(\mathbf{O})$. Washed fibrin glue was incubated in $100 \mathrm{mU} / \mathrm{ml}$ of Plg and $100 \mathrm{U} / \mathrm{ml}$ of urokinase at $37^{\circ} \mathrm{C}$ for $3(\triangle)$ or $24 \mathrm{~h}(\boldsymbol{\Delta})$. Values represent the mean \pm S.D. of four experiments.
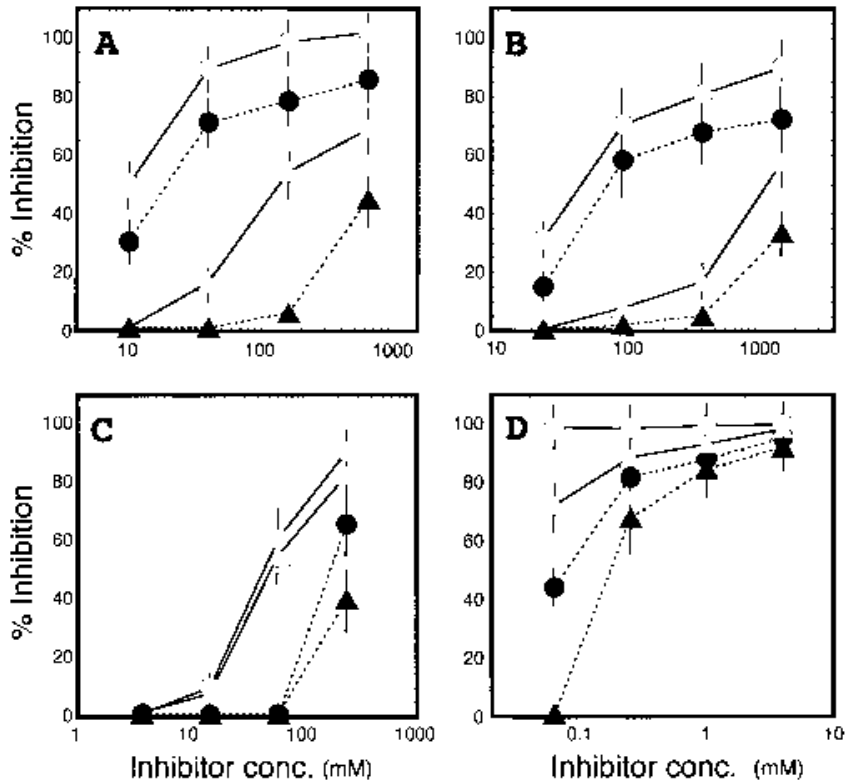

Fig. 3. Effects of Tra (A), Ips (B), Gab (C), and Naf (D) on Lysing Properties of the Fibrin Glues

Unwashed fibrin glue was incubated in $100 \mathrm{U} / \mathrm{ml}$ of urokinase at $37^{\circ} \mathrm{C}$ for $3(\mathrm{O})$ or $24 \mathrm{~h}(\circlearrowleft)$. Washed fibrin glue was incubated in $100 \mathrm{mU} / \mathrm{ml}$ of $\mathrm{Plg}$ and $100 \mathrm{U} / \mathrm{ml}$ of urokinase at $37^{\circ} \mathrm{C}$ for $3(\triangle)$ or $24 \mathrm{~h}(\boldsymbol{\Delta})$. Values represent the mean \pm S.D. of four experiments.

tion to obtain the same level of activity. The reason for this may be that two thirds of the Apr in fibrin glue was released into the medium by the washing treatment.

Ips or Tra in the glue inhibited fibrinolysis dose-dependently similar to Apr, but fibrin glue containing Ips or Tra was gradually lysed with time (Figs. 3A and B). Their activities were remarkably weak compared with that of Apr and were decreased by the washing treatment. The binding affinity of Ips and Tra for fibrin glue may be lower than that of Apr.

Gab inhibited fibrinolysis dose-dependently, similar to Apr, but its activity was slightly affected by the washing treatment (Fig. 3C). On the other hand, Naf completely inhibited fibrinolysis for $3 \mathrm{~h}$ over the concentration range examined, but fibrin glue containing Naf was gradually lysed with time (Fig. 3D). Fibrinolysis of the glue mixed with Naf was slightly accelerated by the washing treatment, and the
Table 1. Inhibitory Properties of Each Anti-fibrinolytic Agent

\begin{tabular}{cccc}
\hline \hline \multirow{2}{*}{ Inhibitor } & \multicolumn{2}{c}{$\mathrm{IC}_{50}(\mathrm{mM})$} & \multirow{2}{*}{$\mathrm{RC}$} \\
\cline { 2 - 3 } & Unwashed (IP) & Washed (IP) & \\
\hline Apr & $0.033(1)$ & $0.093(1)$ & 0.35 \\
Ips & $77(0.0004)$ & $3460(0.00003)$ & 0.022 \\
Tra & $17(0.0019)$ & $770(0.0001)$ & 0.022 \\
Gab & $160(0.0002)$ & $360(0.0004)$ & 0.44 \\
Naf & $0.075(0.44)$ & $0.17(0.55)$ & 0.44 \\
\hline
\end{tabular}

$\mathrm{IC}_{50}$ : concentration causing $50 \%$ inhibition of fibrinolysis, IP: inhibition potency $v$. Apr, RC: remaining coefficient.
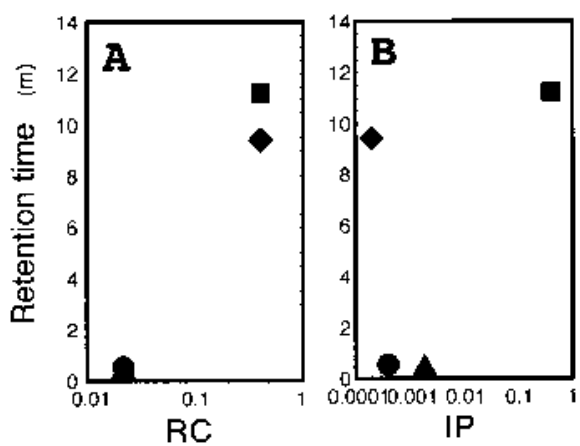

Fig. 4. Relationship between the Hydrophobicity and Inhibitory Properties of Anti-fibrinolytic Agents

- Ips, $\boldsymbol{\Delta}:$ Tra, $\bullet$ Gab, $\mathbf{\square}$ : Naf. A: retention time $v s$. RC $(Y=13.1+7.69 \log X, r=$ $0.99)$. B: retention time $v s$. IP (unwashed glue) $(Y=10.3+1.94 \log X, r=0.51)$.

glue, mixed with $\mathrm{Naf}$ at $0.0625 \mathrm{~mm}$ and washed, was completely lysed after $24 \mathrm{~h}$ incubation. Naf may gradually be degraded with time. These results indicate that the inhibitory activities of the anti-fibrinolytic agents differ remarkably.

Inhibitory Properties of Anti-fibrinolytic Agents To identify the inhibitory properties of each anti-fibrinolytic agent, $\mathrm{IC}_{50}$, IP, and $\mathrm{RC}$ values were compared. As shown in Table 1, in unwashed glue the $\mathrm{IC}_{50}$ of Naf was the lowest of all the anti-fibrinolytic agents. The $\mathrm{IC}_{50}$ of the inhibitor gradually increased in the order Tra, Ips, and Gab. On the other hand, in washed glue the $\mathrm{IC}_{50}$ was gradually increased in the order Naf, Gab, Tra, and Ips. Moreover, in both washed and unwashed glue, the IP of Naf was similar to that of Apr, but the IP of the other inhibitors was remarkably lower than that of Naf and Apr. These results indicate that Naf is the most potent anti-fibrinolytic agent to replace Apr.

The difference in $\mathrm{IC}_{50}$ between washed and unwashed glue may be due to the affinity of the inhibitors; namely, the lower the affinity for the glue, the more inhibitor is released from the glue with washing. In our previous paper, the rate of release of anti-cancer drugs from fibrin glue correlated well with hydrophobicity. ${ }^{16)}$ So the relationship between the RC of each anti-fibrinolytic agent and lipophilicity was studied. As shown in Fig. 4A, a good correlation was observed. IP, on the other hand, was not correlated with the lipophilicity (Fig. 4B). These results indicate that the RC of an anti-fibrinolytic agent is a good indicator of its affinity for fibrin glue, and that the IP is regulated by some specific factor(s) other than lipophilicity.

Effect of Anti-fibrinolytic Agent on the Adhesive Strength of Fibrin Glue The effect of each anti-fibri- 


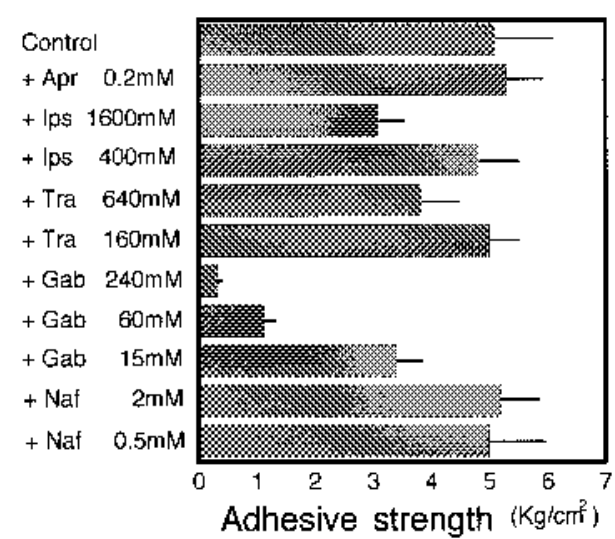

Fig. 5. Effect of Anti-fibrinolytic Agents on the Adhesive Strength of Fibrin Glue

Values represent the mean \pm S.D. of four to six experiments.

nolytic agent on the adhesive strength of fibrin glue was determined by applying glue containing a concentration of inhibitor together with thrombin to ground flat glass, and the strength of the glue was monitored. As shown in Fig. 5, the adhesive strength of the glue containing Naf and Apr was similar to that of control. This strength was slightly decreased by adding a high concentration of Tra or Ips, but at intermediate and low concentrations the strength was similar to that of the glue containing Apr. The strength of the glue with Gab, however, decreased remarkably with concentration. These results indicate that Naf does not affect the adhesive strength of fibrin glue and is the most compatible antifibrinolytic agent to replace Apr.

In this paper, we studied the inhibitory properties of antifibrinolytic agents as substitutes for Apr in fibrin glue produced from human plasma and the physicochemical factor(s) affecting these properties. Fibrin glue without an anti-fibrinolytic agent was quickly lysed, but an anti-fibrinolytic agent delayed fibrinolysis dose-dependently. Naf was the most potent inhibitor and had high affinity for the glue, and while the IP of each inhibitor did not correlate with hydrophobicity, the RC did. All the anti-fibrinolytic agents except Naf affected the adhesive strength of the glue. These results indicate that Naf is the most compatible anti-fibrinolytic agent to replace Apr.

Acknowledgements We gratefully acknowledge the Yamaguchi Red Cross Blood Center for donating human plasma from healthy volunteers that had been excluded by ALT test.

\section{REFERENCES}

1) Radosevich M., Goubran H. A., Burnouf T., Vox Sang., 72, 133-143 (1997).

2) MacCarthy P. M., Transfu. Med. Rev., 7, 173-179 (1993).

3) Alving B. M., Weinstein M. J., Finlayson J. S., Menitove J. E., Fratantoni J. C., Transfusion, 35, 783-790 (1995).

4) Izumi T., Muroi K., Sasaki R., Suzuki T., Nakaki Y., Yoshida M., Hatake K., Sakata Y., Amamiya Y., Miura Y., Jpn. J. Transf. Med., 43, 198 (1997).

5) Saldanha J., Minor P., Br. J. Haematol., 93, 714-719 (1996).

6) Suzuki K., Iwata M., Ito S., Matsui K., Uchida A., Mizoi Y., Human Genetics, 94, 129-135 (1994).

7) Baumann R. E., Henschen A. H., Blood, 82, 2117-2124 (1993).

8) Nakamura S., Sawaguchi A., Gene Geography, 5, 45-50 (1991).

9) van der Velden P. A., Krommenhoek-Van Es T., Allaart C. F., Bertina R. M., Reitsma P. H., Thromb. Haemostasis, 65, 511-513 (1991).

10) Makuuchi H., Naruse Y., Kobayashi T., Yamamoto T., Takahashi T., Watanabe Y., Fuse K., Jpn. J. Transf. Med., 41, 139-144 (1995).

11) Tsuruno T., Suzuki K., Nakamura T., Furukawa H., Sakamoto H., $J$. Jpn. Soc. Autolog. Blood Transf., 4, $41-44$ (1991).

12) Wuthrich B., Schmid P., Schmid E. R., et al., Lancet, 340, 173-174 (1992).

13) Mitsuhata H., Horiguchi Y., Saitoh K., et al., Anesthesiology, 81, 1074-1077 (1994).

14) Yoshida H., Kamiya A., Biol. Pharm. Bull., 21, 1367-1370 (1998).

15) Yoshida H., Hirozane K., Kamiya A., Biol. Pharm. Bull., 22, $1222-$ 1225 (1999).

16) Yoshida H., Yamaoka Y., Shinoyama M., Kamiya A., Biol. Pharm. Bull., 23, 371-374 (2000).

17) Yoshida H., Hirozane K., Kamiya A., Biol. Pharm. Bull., 23, 313317 (2000).

18) Masumoto K., Takeyasu A., Oizumi K., Kobayashi T., Yakugaku Zasshi, 115, 213-220 (1995).

19) Lowry O. H., Rosebrough N. J., Farr A. L., Randall R. J., J. Biol. Chem., 193, 265-275 (1951). 